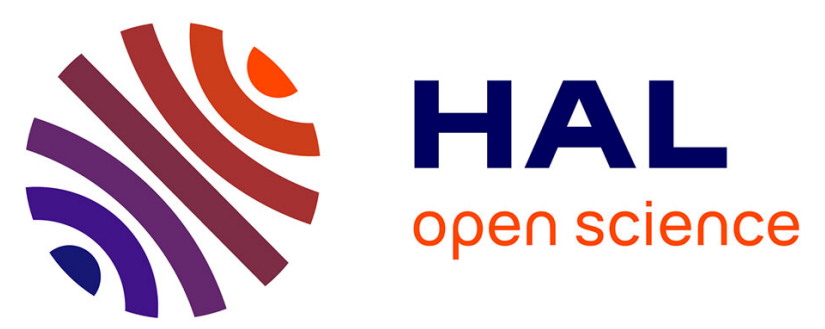

\title{
Incidence and determinants of mortality and morbidity following early antiretroviral therapy initiation in HIV-infected adults in West Africa.
}

\author{
Raoul Moh, Christine Danel, Eugène Messou, Timothèe Ouassa, Delphine
} Gabillard, Amani Anzian, Yao Abo, Roger Salamon, Emmanuel Bissagnene, Catherine Seyler, et al.

\section{To cite this version:}

Raoul Moh, Christine Danel, Eugène Messou, Timothèe Ouassa, Delphine Gabillard, et al.. Incidence and determinants of mortality and morbidity following early antiretroviral therapy initiation in HIVinfected adults in West Africa.: early ART initiation in West Africa. AIDS. Official journal of the international AIDS Society, 2007, 21 (18), pp.2483-91. 10.1097/QAD.0b013e3282f09876 . inserm00173522

HAL Id: inserm-00173522 https://www.hal.inserm.fr/inserm-00173522

Submitted on 6 Jul 2009

HAL is a multi-disciplinary open access archive for the deposit and dissemination of scientific research documents, whether they are published or not. The documents may come from teaching and research institutions in France or abroad, or from public or private research centers.
L'archive ouverte pluridisciplinaire HAL, est destinée au dépôt et à la diffusion de documents scientifiques de niveau recherche, publiés ou non, émanant des établissements d'enseignement et de recherche français ou étrangers, des laboratoires publics ou privés. 


\title{
Incidence and determinants of mortality and morbidity following early ART initiation in HIV-infected adults in West Africa
}

\section{Accepted for publication in AIDS}

\author{
Raoul Moh ${ }^{1}$, Christine Danel $^{1}$, Eugène Messou ${ }^{1}$, Timothèe Ouassa ${ }^{1,2}$, Delphine \\ Gabillard $^{1}$, Amani Anzian ${ }^{1}$, Yao Abo ${ }^{1}$, Roger Salamon ${ }^{1,4}$, Emmanuel Bissagnene ${ }^{1,3}$, \\ Catherine Seyler $^{1,4}$, Serge Eholié ${ }^{1,3}$, Xavier Anglaret ${ }^{1,4}$ \\ ${ }^{1}$ Trivacan ANRS 1269 study group, Abidjan \\ ${ }^{2}$ Centre de Diagnostic et de Recherches sur le SIDA (CeDReS), CHU de Treichville, Abidjan \\ ${ }^{3}$ Service des Maladies Infectieuses et Tropicales, CHU de Treichville, Abidjan \\ ${ }^{4}$ INSERM U593, Bordeaux, France
}

\section{Correspondence:}

Dr Xavier Anglaret, MD, PhD

INSERM U593

Université Bordeaux 2

146 rue Léo Saignat

33076 Bordeaux Cedex

France

Tel : +33 557571765 Fax: +33557574528

e-mail : Xavier.Anglaret@isped.u-bordeaux2.fr

This study was supported by the French Agence Nationale de Recherches sur le SIDA et les hépatites virales (ANRS, Paris, France, grant ANRS 12136), and the Ivoirian Ministry of Public Health within the collaborative Programme PAC-CI.

Running head: early ART initiation in West Africa 


\section{Abstract (251 words)}

Objective: To estimate the incidence and risk factors of mortality and severe morbidity during the first months following antiretroviral treatment (ART) initiation in West African adults.

Methods: Cohort study in Abidjan. 792 adults started ART with a median CD4 count of $252 / \mathrm{mm}^{3}$ and were followed during a median of 8 months. Severe morbidity was defined as all WHO stage 3 or 4-defining morbidity events other than oral candidiasis.

Results: In patients with pre-ART CD4 count $<200$, at $200-350$ and $>350 / \mathrm{mm}^{3}$, the incidence of mortality was 5.0 [95\%CI 2.6-8.7], 1.7 [0.6-3.8] and 0.0 [0.0-3.4]/100 person-years, and the incidence of severe morbidity was 13.3 [95\%CI 9.0-19.1], 9.5 [6.2-12.9] and 7.9 [3.4$15.5] / 100$ person-years, respectively. The most frequent diseases were invasive bacterial diseases (32/65 episodes, 49\%) and tuberculosis (25/65 episodes, 38\%). Both diseases followed the same curve of decreasing incidence over time. Patients who experienced severe morbidity had higher risks of mortality, of virological failure and of immunological failure. Other independent risk factors for mortality and/or severe morbidity were: at baseline, a high viral load, an advanced clinical stage, a past history of tuberculosis, a low BMI, a low haemoglobin, and a low CD4 count; during follow-up: a low CD4 count and a persistently detectable viral load.

Conclusion: These data give new arguments to reinforce the hypothesis that, in this region,

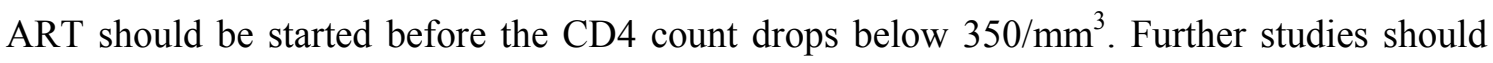
assess whether patients with low BMI, low haemoglobin, high viral load or past history of tuberculosis should start ART earlier.

Keywords: sub-Saharan Africa; tuberculosis; bacterial diseases; HAART; risk factors; morbidity; antiretrovirals 


\section{Introduction}

In sub-Saharan Africa, millions of HIV-infected people are about to start antiretroviral treatment (ART) within the next few years ${ }^{1-3}$. Mortality within the first months following ART initiation was shown to be higher in sub-Saharan Africa than in industrialized countries ${ }^{4}$.

Scaling-up the access to ART in African settings where tools for diagnosing and treating opportunistic infections are less available than in high-resource settings entails the necessity to prevent patients who started ART to die from preventable or curable diseases. It is thus important to document the causes of morbidity that continue to occur in patients receiving ART, and to identify patients at higher risk of dying or developing severe morbidity once they started ART. Previous studies have already identified tuberculosis, acute sepsis, cryptococcosis and toxoplasmosis as key causes of mortality in patients starting ART with low CD4 count ${ }^{5-8}$.

We estimated the incidence and risk factors of all causes of severe morbidity and mortality within the first months following early ART initiation in 792 HIV-infected adults in Abidjan, the economic capital city of Côte d'Ivoire.

\section{Methods}

\section{Patients}

In December 2002, a multicentre randomised trial (Trivacan ANRS 1269 trial) was launched in Abidjan ${ }^{9}$. The protocol was approved by the ethics committee of the Ivorian Ministry of Health and the Institutional Review Board of the Agence de Recherche sur le SIDA et les Hépatites Virales (ANRS). The main objective of this trial was to assess various structured ART interruptions strategies. The trial was designed in two phases. Patients were included in the first phase ("ART initiation phase") if they met the following criteria: age $\geq 18$ years, no past history of ART, CD4+ T-cell (CD4) count between 150 and $350 / \mathrm{mm}^{3}$ or CD4 percentage between $12.5 \%$ and $20.0 \%$, living in Abidjan and written informed consent. At inclusion, all patients started continuous ART and were followed under cohort procedures. After at least six months in the ART initiation phase, patients with undetectable viral load and CD4 count > $350 / \mathrm{mm}^{3}$ were randomised into the "ART interruptions strategies" phase. The criteria for being randomised had to be reached before 18 months of treatment. This explains why the CD4 criterion for being included in the ART initiation phase was atypically high, compared to the CD4 starting measure in the international guidelines at the time when the trial was started.

We present here data on severe morbidity that occurred during the ART initiation phase of the Trivacan trial. 


\section{Follow-up}

The procedures of the ART initiation phase have been previously described ${ }^{10,11}$. In summary: at enrolment, patients started either zidovudine (ZDV)-lamivudine (3TC)-efavirenz or ZDV3TC-Indinavir/ritonavir (800/100 mg twice daily). CD4 count (True Count ${ }^{\circledR}$ technique on FACScan $^{\circledR}$, Becton Dickinson) and plasma HIV-1 RNA (real-time PCR on Taq Man technology Abi Prism 7000, Applied Biosystems, threshold of detectability at 300 copies $/ \mathrm{mL})^{12}$ were measured every three months. Cotrimoxazole was systematically given to all patients. All clinical events were reviewed by an event documentation committee. The diagnostic criteria were the same as those used in the ANRS 1203 cohort study ${ }^{13,14}$. Tuberculosis was defined as definitive when a mycobacterium of the tuberculous group was isolated, and as presumptive when all the following criteria were met: (i) consistent clinical picture, (ii) presence of acid-fast bacilli on sputum sample, bronchoalveolar lavage or normally sterile body fluid or tissue from a site other than lungs or no other clinically significant pathogen isolated, (ii) unsuccessful response to standard antibiotherapy and (iii) successful response to standard antituberculous therapy. Bacterial diseases with positive blood culture for non-typhi Salmonella were classified into WHO clinical stage 4. Bacterial diseases with positive blood culture for other clinically significant pathogen were classified into WHO clinical stage 3 . When blood cultures were negative, the following bacterial diseases were classifying into WHO clinical stage 3: pneumonia, pleurisy, enteritis with stool cultures positive for non-typhi Salmonella or Shigella sp, salpyngitis, pyelonephritis, prostatitis, orchiepididymitis, meningitis, endocarditis, pyomyositis, pericarditis, and deep-abscess. Diseases were taken into account only if the date of the first symptoms was posterior to the date of ART initiation.

All care was free-of-charge, and patients were reimbursed for the cost of transportation without making any distinction between scheduled and unscheduled visits. In the study centres, participants were attended to by nurses, physicians, and social workers dedicated fulltime to the study. Patients with any severe symptom were attended to first, irrespective of whether the visit was unscheduled or scheduled.

\section{Statistical analyses}

All patients included in the "ART initiation phase" of the Trivacan trial were eligible for the present study. They were excluded from the analyses if they were HIV-2 infected, if they had undetectable viral load on ART initiation, or if they had an ongoing episode of severe morbidity at the time when they started ART. Baseline was the date of ART initiation. The date of the end of study was the date of the 18-months visit following ART initiation, or the date when the patient was randomised into the ART interruption strategies if $<$ ART initiation +18 months. 
First, we estimated, overall and by baseline characteristics: the incidence of mortality, the incidence of severe morbidity, the Kaplan Meier probability of reaching virological success of ART and the Kaplan Meier probability of responding immunologically to ART. Severe morbidity was defined as all WHO stage 3 or 4-classifying morbidity events (with the exception of oral candidiasis). Virological success was defined as the first time when a viral load was measured as undetectable. Immunological response was defined as the first time when a gain in CD4 of at least 50 cells $/ \mathrm{mm}^{3}$ since baseline was observed. The trends for incidence of mortality and morbidity over time were tested using Poisson regression.

Second, we studied factors associated with death and with severe morbidity using a multivariate Cox proportional-hazard regression analysis. Baseline explicative variables were age, sex, body mass index, WHO clinical stage combined with past history of successfully treated tuberculosis (stage 1 or 2 versus stage 3 or 4 without tuberculosis past history versus stage 3 or 4 with tuberculosis past history), baseline haemoglobin, baseline CD 4 count and baseline plasma HIV-1 viral load. Follow-up explicative variables were follow-up CD4 counts and follow-up viral loads (detectable versus undetectable). In a first set of analyses, only baseline variables were included in the multivariate model. In a second set of analyses, both baseline and follow-up variables were included in the model. For mortality analysis, severe morbidity was included in the second set of analyses as a time-independent explicative variable.

Finally, we studied whether severe morbidity was associated with virological and immunological outcomes. The association of each biological outcome with follow-up severe morbidity was studied using a multivariate Cox analysis, adjusting on all characteristics associated with the corresponding outcome with a $\mathrm{p}<0.20$ in univariate analysis.

For the morbidity incidence rate calculation and for the analyses of factors associated with morbidity, we only took into account the first event.

All Cox proportional-hazard models were checked for the proportional hazards condition. 


\section{Results}

\section{Patients and follow-up}

Of the 840 adults enrolled in the Trivacan trial, 48 were excluded from the present study because they were infected with HIV-2 $(n=16)$, they had an undetectable viral load at baseline $(n=9)$, or they had a prevalent episode of tuberculosis at the time when they started ART $(\mathrm{n}=23)$. The 792 patients who remained in analyses were predominantly with a CD4 count $>$ $200 / \mathrm{mm}^{3}(71 \%)$ and at WHO stage 1 or $2(64 \%)$ (table 1). During follow-up, 370 (47\%) patients were randomized in the Trivacan trial at seven months, $155(20 \%)$ at 10 months, 51 $(6 \%)$ at 13 months, $28(3.5 \%)$ at 16 months, and $188(24 \%)$ were never randomised. Of the latter, nine were lost-to-follow-up before study termination.

\section{Causes of severe morbidity and mortality}

During follow-up, 18 patients died (including 8 with at least one documented episode of severe morbidity between inclusion and death) and 59 patients presented 65 episodes of severe morbidity. Of these episodes, $43(66 \%)$ were recorded for the first time at unscheduled visits versus $22(34 \%)$ at scheduled visits.

The episodes of severe morbidity were invasive bacterial diseases (28 patients, 32 episodes), tuberculosis (23 patients, 25 episodes), and other WHO stage 3 or 4 classifying diseases ( 8 patients, 8 episodes). The latter included isosporiasis $(n=1)$, cerebral toxoplasmosis $(n=1)$, Kaposi's sarcoma $(n=2)$, unexplained chronic diarrhea $(n=2)$, chronic genital herpes simplex virus infection $(n=1)$ and cryptosporidiosis $(n=1)$. The 32 episodes of bacterial diseases were 16 pneumonia, five isolated bacteraemia, four enteritis, three pyelonephritis, one pyomyositis, one deep abscess, one prostatitis and one salpyngitis. At the time when the first bacterial episode occurred, the median last available CD4 count was $281 / \mathrm{mm}^{3}$ [IQR $197-406$ ] and the median time since ART initiation was 3.0 months [IQR 1.3-4.5]). A pathogen was isolated in 18 of these 32 episodes, including in blood culture in 12 episodes. The 18 bacterial strains were Streptococcus pneumoniae $(\mathrm{n}=6)$, non-typhi Salmonella $(\mathrm{n}=6)$, Escherichia coli $(\mathrm{n}=4)$, Staphylococcus aureus $(\mathrm{n}=1)$ and Enterobacter cloacae $(\mathrm{n}=1)$. The 25 episodes of tuberculosis (definitive 68\%), were pulmonary (64\%), extra-pulmonary (24\%), and both $(12 \%)$. At the time when the first tuberculosis episode occurred, the median last available CD4 count was 235/ $\mathrm{mm}^{3}$ [IQR 167-315] and the median time since ART initiation was 3.7 months [IQR 0.5-5.4]).

In the 18 patients who died, a cause of death could be identified in nine cases: tuberculosis $(n=3)$, cerebral toxoplasmosis $(n=1)$, Kaposi's sarcoma $(n=1)$, isolated bacteraemia $(n=1)$, malaria $(n=1)$, cardiac insufficiency $(n=1)$ and trauma $(n=1)$. Of the remaining nine patients, three died with symptoms of undiagnosed origin (one pleuritis, one unexplained chronic 
diarrhea, one acute unexplained fever), and the other six died at home or elsewhere without having attended the care centre before death.

\section{Overall incidence and risk factors of severe morbidity and mortality}

During the entire follow-up, the incidence of severe morbidity was estimated at 10.6/100 patient-years [P-Y] (95\%CI 8.10-13.10), overall and 13.3/100 P-Y, 9.5/100 P-Y and 7.9/100 $\mathrm{P}-\mathrm{Y}$ in patients with pre-ART CD4 count $<200$, at $200-350$ and $>350 / \mathrm{mm}^{3}$, respectively.

The incidence of death was estimated at 2.6/100 P-Y (95\%CI 1.5-4.1) overall, and 5.0/100 P$\mathrm{Y}, 1.7 / 100 \mathrm{P}-\mathrm{Y}$, and $0.0 / 100 \mathrm{P}-\mathrm{Y}$ in patients with pre-ART CD4 count $<200$, at 200-350 and $>350 / \mathrm{mm}^{3}$, respectively.

Figure 1 shows the incidence of severe morbidity (figure 1A) and mortality (figure 1B) by baseline characteristics. In univariate analysis, both mortality and severe morbidity were significantly associated with body mass index, haemoglobin, and WHO clinical stage. In addition, mortality was significantly associated with baseline CD4 count while the association between severe morbidity and CD4 count did not reached significance, and severe morbidity was significantly associated with baseline viral load level while the association between mortality and baseline viral load did not reach significance.

Table 2 and 3 show the results of the multivariate analysis of the association between severe morbidity or mortality with baseline characteristics on the one hand and with follow-up characteristics (adjusting on baseline characteristics) on the other hand. As shown in these tables, severe morbidity was independently associated with an advanced baseline WHO stage, a low baseline haemoglobin, a high pre-ART viral load, a low follow-up CD4 count and a persistently detectable viral load during follow-up. When considering separately the main groups of severe morbidity, the two variables most strongly associated with the risk of tuberculosis were a past history of tuberculosis and a low follow-up CD4 count, whereas the variable most strongly associated with severe bacterial diseases was a high pre-ART viral load (table 2). Mortality was independently associated with a low baseline body mass index, a low baseline or follow-up CD4 count, a persistently detectable viral load during follow-up, and the occurrence of at least one episode of severe morbidity during follow-up (table 3 ). There was no significant association between age or sex and mortality or severe morbidity. 


\section{Evolution of morbidity and mortality over time}

During the first, second and third quarter following ART initiation, the overall incidence of severe morbidity was 16.6 (95\%CI 10.9-22.4), 10.2 (95\%CI 6.1-15.9) and 6.6/100 P-Y (95\% CI 2.8-12.9), respectively (trend over time: $\mathrm{p}=0.03$ ), and the incidence of mortality was 3.1 (95\%CI 1.1-6.6), 1.0 (95\%CI 0.1-3.7) and 1.5/100 P-Y (95\%CI 0.2-5.5), respectively (trend over time: $\mathrm{p}=0.33$ ). Figure 2 shows the evolution in time of the incidence of mortality, overall severe morbidity, tuberculosis and bacterial diseases since ART initiation. The incidence rate of morbidity was 25.2 (first quarter), 13.2 (second quarter) and 4.7/100 P-Y (third quarter) in patients with pre-ART CD4 count $<200 / \mathrm{mm}^{3}$ (trend over time: $\mathrm{p}=0.02$ ), 15.1 (first quarter), 8.3 (second quarter) and 8.2/100 P-Y (third quarter) in patients with preART CD4 count at $200-349 / \mathrm{mm}^{3}$ (trend over time: $\mathrm{p}=0.27$ ) and 8.0 (first quarter), 10.9 (second quarter) and 5.6/100 P-Y (third quarter) in patients with pre-ART CD4 count $\geq$ $350 / \mathrm{mm}^{3}$ (trend over time: $\mathrm{p}=0.80$ ).

\section{Association between severe morbidity and virological or immunological outcomes}

The probability of reaching at least once viral load undetectability was estimated at $0.82,0.95$ and 0.97 at 6,12 and 18 months, respectively. In multivariate analysis, patients who had at least one severe morbidity event during follow-up had an adjusted hazard ratio of reaching viral load delectability of $0.68(95 \% \mathrm{CI} 0.51-0.91, \mathrm{p}=0.01)$. Of the 59 patients with at least one episode of severe morbidity, 41 had their first episode before viral load undetectability was noticed, and 18 had their first episode after having reached at least once viral load undetectability.

The probability of having at least once a gain in CD4 $>50 / \mathrm{mm}^{3}$ since baseline was estimated at $0.79,0.94$ and 0.96 at 6,12 and 18 months, respectively. In multivariate analysis, patients who had at least one severe morbidity event during follow-up had an adjusted hazard ratio of reaching a gain in CD4 $>50 / \mathrm{mm}^{3}$ of $0.64(95 \% \mathrm{CI}$ 0.48-0.85, $\mathrm{p}=0.002)$.

\section{Discussion}

Our patients started ART with a much more moderate level of pre-ART immunosuppression as compared with the vast majority of adults who have been starting ART in sub-Saharan Africa for the last years ${ }^{4-6,8,15-22}$. They were followed under cohort procedures with a standardised documentation of all morbidity events and a low rate of follow-up.

The ART-LINC team previously reported that patients starting ART in low-income settings had a higher hazard of mortality than those starting ART in high income settings during the first few months following ART initiation ${ }^{4}$. In our study, the rapidly declining rate over time of tuberculosis and invasive bacterial diseases may partly explain these findings. 
Our patients were followed under trial conditions, with all care free of charge. The rate of mortality would have been likely to be higher if these patients would have been followed-up in field conditions. Despite optimal conditions of access to care, the rate of mortality was not null in patients with pre-ART CD4 count at $200-350 / \mathrm{mm}^{3}$. Furthermore, even if most patients who experienced severe morbidity did not die, the occurrence of at least one severe morbidity event after ART initiation was significantly associated with impaired medium term immunological and virological outcomes. These data suggest that starting ART before the CD4 count drops below 350/ $\mathrm{mm}^{3}$ in HIV-infected adults in Côte d'Ivoire may prevent short term mortality on ART and improve short term immunological and virological treatment outcomes by reducing the rate of severe morbidity.

Data from CD4-guided structured treatment interruptions strategies trials performed in industrialised and low resource countries showed that patients "off" ART had higher severe morbidity and mortality rates than those "on" ART, even at CD4 counts higher than those currently recommended in international guidelines for ART initiation ${ }^{9,23}$. This led some experts to suggest that the issue of "when to start ART" should be rapidly addressed through trials comparing the current starting criteria with earlier criteria ${ }^{24}$. The spectrum of HIVmorbidity in sub-Saharan Africa gives specific arguments to suggest that ART should be started earlier than currently recommended. In a cohort study of HIV-infected untreated adults in South Africa, the risk of AIDS in patients with a CD4 count at $250-350 / \mathrm{mm}^{3}$ was 1.9 times greater than the risk previously reported from European cohorts ${ }^{25}$. In sub-Saharan Africa before the ART era, the rates of HIV-associated tuberculosis and invasive bacterial diseases and, consecutively, the rate of severe morbidity at early stages of immunosupression - were shown to be higher than in high income countries. The high rate of bacterial diseases, among others, led WHO experts to recommend that cotrimoxazole prophylaxis should be started earlier in Africa than in industrialized countries ${ }^{26-28}$. In this context of early severe morbidity, starting ART at earlier stage of immunosupression would be logical.

To refine the criteria for starting ART in Africa, the pre-ART factors associated with the outcomes need to be better documented, in order to treat first and foremost patients who will be at higher risk of failing treatment. The CD4 count is not the only pre-ART factor to predict the events occurring after ART initiation. In our study, patients with low haemoglobin level, low body mass index and advanced WHO stage were at higher risk of dying and/or developing severe morbidity, as previously reported by others ${ }^{4,5,16-18}$. The CD4 count and plasma viral load measurements performed after ART initiation were stronger risk factors for the on-ART severe morbidity and mortality than the pre-ART CD4 and viral load values, even during the first year of treatment ${ }^{8,29,30}$. A high plasma viral load was more strongly associated with the occurrence of severe bacterial diseases than with the occurrence of tuberculosis. Finally, a past episode of successfully treated tuberculosis before ART initiation was independently associated with the risk that a new episode of tuberculosis would occur 
once ART has been started. This is the second time that an association between past history of tuberculosis and incident tuberculosis on ART is reported in Côte d'Ivoire ${ }^{14}$. Interestingly, though, such association was not found in other studies performed in South Africa ${ }^{8,31}$. There could be two explanations for this divergence. First, the history of tuberculosis is not an easy variable to record exhaustively in routine care conditions ${ }^{32}$. The longer the time since a past episode of tuberculosis occurred, the higher the risk that a patient may omit to declare it but also the higher the risk that a relapse may occur ${ }^{8}$. Second, the local context of tuberculosis care, for example the percentage of patients who self-administer their anti-tuberculosis treatment compared to the percentage of those who receive directly observed therapy, may lead tuberculosis to be more likely to relapse on ART in some settings compared with others 33,34 .

The main limit of our study was that patients who reached criteria for ART success after seven months were randomised into the Trivacan trial and therefore left the study. Thus, after seven months, the follow-up of the healthier patients was censored whereas the sickest patients remained in follow-up. This could have led to an overestimation of the mortality and morbidity rates after seven months. If no follow-up censoring had been made, the decreasing rate of mortality and morbidity over time would have probably been even more marked.

In conclusion, this large cohort study of the mortality and morbidity in adults who started ART at intermediate stages of immunosuppression in West Africa gives new arguments to reinforce the hypothesis that, in this region, ART should be started before the CD4 count drops bellow $350 / \mathrm{mm}^{3}$. Further studies should assess whether patients with low BMI, low haemoglobin, high viral load, clinical stage 3 or past history of active tuberculosis should start ART earlier. 


\section{Acknowledgments}

We would like to thank Joanna Orne-Gliemann (INSERM U593) for her grammatical and editing contributions

Contributors:

R Moh, C Danel, X Anglaret, E Bissagnene and R Salamon sought funding for the study and were responsible for overall study coordination. E Messou, C Seyler, A Anzian, Y Abo and S Eholié were responsible for patients clinical care in the study centre. T Ouassa led all biological aspects. D Gabillard was the study statistician. X Anglaret, R Moh, D Gabillard and $\mathrm{C}$ Danel drafted the manuscript, which all authors subsequently reviewed, edited and approved. 


\section{References}

1. PEPFAR. Latest 2007 PEPFAR Treatment Results, 3/31/2007. http://www.pepfar.gov/press/85520.htm

2. The Global Fund to fight AIDS tam. Partners in Impact - Results Report 2007; http://www.theglobalfund.org/en/files/about/replenishment/oslo/Progress\%20Report.pdf

3. WHO/UNAIDS/UNICEF. Towards Universal Access. Scaling up priority HIV/AIDS interventions in the health sector. Progress Report, April 2007. http://www.who.int/hiv/mediacentre/universal_access_progress_report_en.pdf

4. Braitstein P, Brinkhof MW, Dabis F, Schechter M, Boulle A, Miotti P, et al. Mortality of HIV-1-infected patients in the first year of antiretroviral therapy: comparison between low-income and high-income countries. Lancet 2006;367:817-824.

5. Etard JF, Ndiaye I, Thierry-Mieg M, Gueye NF, Gueye PM, Laniece I, et al. Mortality and causes of death in adults receiving highly active antiretroviral therapy in Senegal: a 7-year cohort study. AIDS 2006;20:1181-9.

6. Seyler C, Anglaret X, Dakoury-Dogbo N, Messou E, Touré S, Danel C, et al. Medium-term survival, morbidity and immunovirological evolution in HIV-infected adults receiving antiretroviral therapy, Abidjan, Côte d'Ivoire. Antivir Ther 2003;8:385-393.

7. Lawn SD, Bekker LG, Myer L, Orrell C, Wood R. Cryptococcocal immune reconstitution disease: a major cause of early mortality in a South African antiretroviral programme. AIDS 2005;19:2050-2.

8. Lawn SD, Myer L, Bekker LG, Wood R. Burden of tuberculosis in an antiretroviral treatment programme in sub-Saharan Africa: impact on treatment outcomes and implications for tuberculosis control. AIDS 2006;20:1605-12.

9. Danel C, Moh R, Minga A, Anzian A, Ba-Gomis O, Kanga C, et al. CD4-guided structured antiretroviral treatment interruption strategy in HIV-infected adults in west Africa (Trivacan ANRS 1269 trial): a randomised trial. Lancet 2006;367:1981-1989.

10. Danel C, Moh R, Anzian A, Abo Y, Chenal H, Guehi C, et al. Tolerance and acceptability of an efavirenz-based regimen in 740 adults (Predominantly women) in West Africa. J Acquir Immune Defic Syndr 2006;42:29-35.

11. Moh R, Danel C, Sorho S, Sauvageot D, Anzian A, Minga A, et al. Haematological changes in adults receiving a zidovudine-containing HAART regimen in combination with cotrimoxazole in Cote d'Ivoire. Antivir Ther 2005;10:615-24.

12. Rouet F, Ekouevi DK, Chaix ML, Burgard M, Inwoley A, Tony TD, et al. Transfer and Evaluation of an Automated, Low-Cost Real-Time Reverse Transcription-PCR Test for Diagnosis and Monitoring of Human Immunodeficiency Virus Type 1 Infection in a West African Resource-Limited Setting. J Clin Microbiol 2005;43:2709-2717.

13. Anglaret X, Messou E, Ouassa T, Toure S, Dakoury-Dogbo N, Combe P, et al. Pattern of bacterial diseases in a cohort of HIV-1 infected adults receiving cotrimoxazole prophylaxis in Abidjan, Cote d'Ivoire. AIDS 2003;17:575-584.

14. Seyler C, Toure S, Messou E, Bonard D, Gabillard D, Anglaret X. Risk Factors for Active Tuberculosis Following Antiretroviral Treatment Initiation in Abidjan. Am J Respir Crit Care Med 2005;172:123-127. 
15. Ferradini L, Jeannin A, Pinoges L, Izopet J, Odhiambo D, Mankhambo L, et al. Scaling up of highly active antiretroviral therapy in a rural district of Malawi: an effectiveness assessment. Lancet 2006;367:1335-42.

16. Stringer JS, Zulu I, Levy J, Stringer EM, Mwango A, Chi BH, et al. Rapid scale-up of antiretroviral therapy at primary care sites in Zambia: feasibility and early outcomes. JAMA 2006;296:782-93.

17. Laurent C, Ngom Gueye NF, Ndour CT, Gueye PM, Diouf M, Diakhate N, et al. Longterm benefits of highly active antiretroviral therapy in Senegalese HIV-1-infected adults. J Acquir Immune Defic Syndr 2005;38:14-7.

18. Zachariah R, Fitzgerald M, Massaquoi M, Pasulani O, Arnould L, Makombe S, et al. Risk factors for high early mortality in patients on antiretroviral treatment in a rural district of Malawi. AIDS 2006;20:2355-60.

19. Calmy A, Pinoges L, Szumilin E, Zachariah R, Ford N, Ferradini L. Generic fixed-dose combination antiretroviral treatment in resource-poor settings: multicentric observational cohort. AIDS 2006;20:1163-9.

20. Weidle PJ, Wamai N, Solberg P, Liechty C, Sendagala S, Were W, et al. Adherence to antiretroviral therapy in a home-based AIDS care programme in rural Uganda. Lancet 2006;368:1587-94.

21. Wester CW, Kim S, Bussmann H, Avalos A, Ndwapi N, Peter TF, et al. Initial response to highly active antiretroviral therapy in $\mathrm{HIV}-1 \mathrm{C}$-infected adults in a public sector treatment program in Botswana. J Acquir Immune Defic Syndr 2005;40:336-43.

22. Coetzee D, Hildebrand K, Boulle A, Maartens G, Louis F, Labatala V, et al. Outcomes after two years of providing antiretroviral treatment in Khayelitsha, South Africa. AIDS 2004;18:887-95.

23. Strategies for Management of Antiretroviral Therapy (SMART) Study Group. CD4+ count-guided interruption of antiretroviral treatment. N Engl J Med 2006;3556:2283-96.

24. WHO. Antiretroviral therapy for HIV infection in adults and adolescents in resourcelimited settings: towards universal access. Recommendations for a public health approach. 2006 revision.

http://www.who.int/hiv/pub/guidelines/WHO\%20Adult\%20ART\%20Guidelines.pdf.

25. Badri M, Lawn S, Wood R. Short-term risk of AIDS or death in people infected with HIV-1 before antiretroviral therapy in South Africa: a longitudinal study. Lancet 2006;368:1254-9.

26. WHO. WHO Expert Consultation on Cotrimoxazole Prophylaxis in HIV Infection. WHO technical report series. Reference number: WHO/HIV/2006.01.

http://www.who.int/hiv/pub/meetingreports/ctx/en

27. Mermin J, Lule J, Ekwaru JP, Malamba S, Downing R, Ransom R, et al. Effect of cotrimoxazole prophylaxis on morbidity, mortality, CD4-cell count, and viral load in HIV infection in rural Uganda. Lancet 2004;364:1428-34.

28. Anglaret X, Chêne G, Attia A, Toure S, Lafont S, Combe P, et al. Early chemoprophylaxis with trimethoprim-sulphamethoxazole for HIV-1-infected adults in Abidjan, Côte d'Ivoire: a randomised trial. Lancet 1999;353:1463-8. 
29. Lawn SD, Myer L, Harling G, Orrell C, Bekker LG, Wood R. Determinants of mortality and nondeath losses from an antiretroviral treatment service in South Africa: implications for program evaluation. Clin Infect Dis 2006;43:770-6.

30. Anastos K, Barron Y, Cohen MH, Greenblatt RM, Minkoff H, Levine A, et al. The prognostic importance of changes in CD4+ cell count and HIV-1 RNA level in women after initiating highly active antiretroviral therapy. Ann Intern Med 2004;140:256-64.

31. Lawn SD, Badri M, Wood R. Risk factors for tuberculosis among HIV-infected patients receiving antiretroviral treatment. Am J Respir Crit Care Med 2005;172:1348; author reply $1348-9$.

32. Harries AD, Hargreaves NJ, Kwanjana JH, Salaniponi FM. Relapse and recurrent tuberculosis in the context of a national tuberculosis control programme. Trans R Soc Trop Med Hyg 2000;94:247-9.

33. Balasubramanian VN, Oommen K, Samuel R. DOT or not? Direct observation of antituberculosis treatment and patient outcomes, Kerala State, India. Int J Tuberc Lung Dis 2000;4:409-13.

34. Frieden TR. Lack of directly observed treatment affects tuberculosis relapse rates. Am J Respir Crit Care Med 2006;173:359; author reply 359. 
Table 1. Baseline and follow-up characteristics of the 792 patients

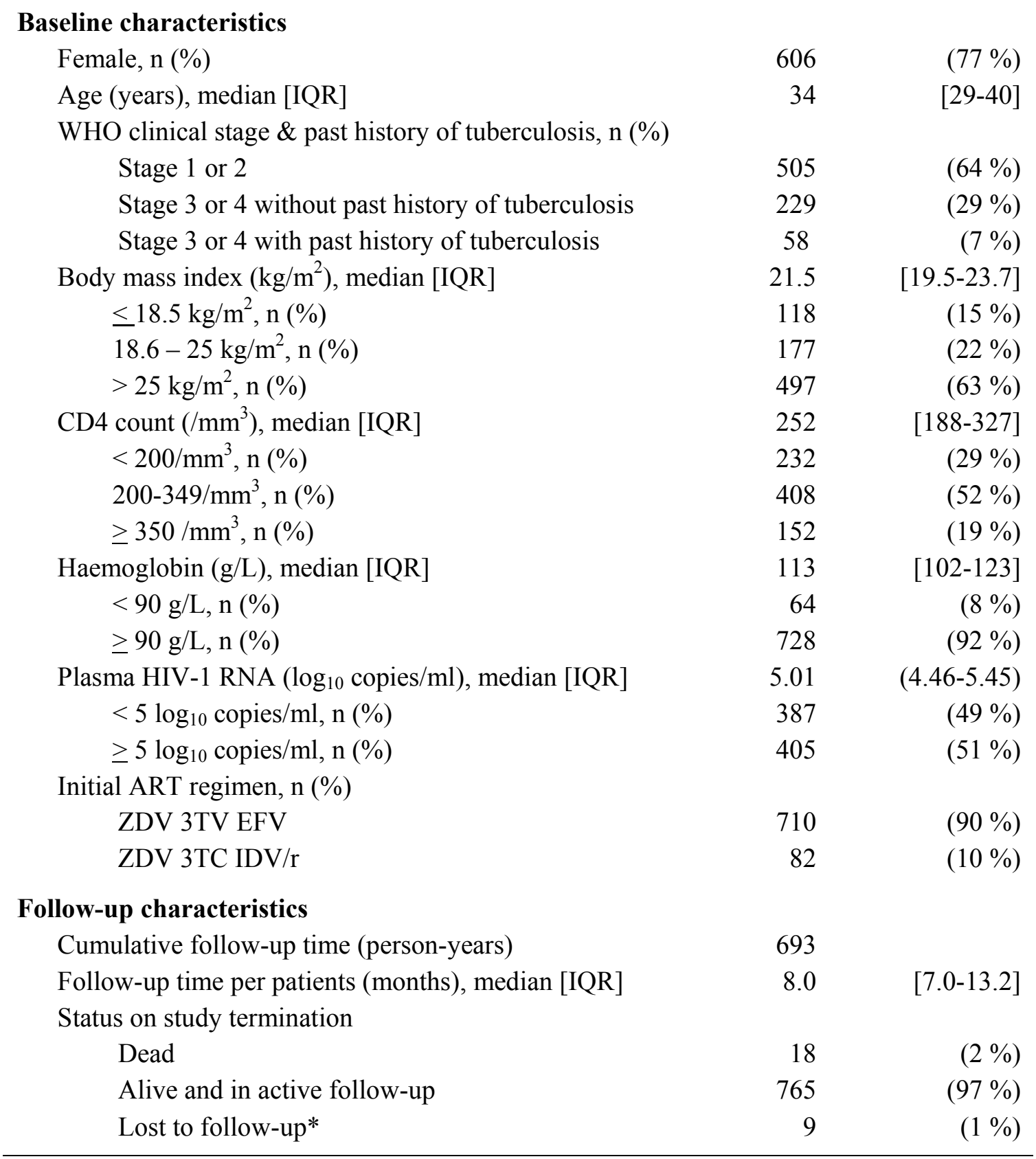

\section{Footnotes for table 1}

Lost to follow-up: last contact with study team $>1$ day at study termination and no further vital status information until September $30^{\text {st }} 2006$

IQR: interquartile range 
Table 2. Factors associated with the risk of overall severe morbidity, tuberculosis, and invasive bacterial diseases after ART initiation: multivariate Cox hazards proportional regression analysis.

\begin{tabular}{|c|c|c|c|c|c|c|c|c|c|}
\hline & \multicolumn{3}{|c|}{ Overall severe morbidity } & \multicolumn{3}{|c|}{ Bacterial diseases } & \multicolumn{3}{|c|}{ Tuberculosis } \\
\hline & HR & $(95 \mathrm{CI} \%)$ & $\mathrm{p}$ & HR & $(95 \mathrm{CI} \%)$ & $\mathrm{p}$ & HR & $(95 \mathrm{CI} \%)$ & $\mathrm{P}$ \\
\hline \multicolumn{10}{|l|}{ Baseline* } \\
\hline WHO staging and TB history vs. stage 1or 2 & & & 0.01 & & & 0.49 & & & 0.01 \\
\hline Stage 3 or 4 without past history of TB & 1.72 & $(1.01 ; 2.94)$ & 0.05 & 1.62 & $(0.73 ; 3.59)$ & 0.24 & 1.59 & $(0.63 ; 4.02)$ & 0.33 \\
\hline Stage 3 or 4 with past history of TB & 2.78 & $(1.38 ; 5.61)$ & 0.004 & 1.45 & $(0.41 ; 5.14)$ & 0.56 & 4.73 & $(1.70 ; 13.13)$ & 0.003 \\
\hline Haemoglobin $<90 v s . \geq 90 \mathrm{~g} / \mathrm{L}$ & 2.11 & $(1.13 ; 3.94)$ & 0.02 & 1.19 & $(0.39 ; 3.59)$ & 0.76 & 4.35 & $(1.72 ; 10.97)$ & 0.002 \\
\hline Viral load $>5 v s . \leq 5 \log 10$ copies $/ \mathrm{ml}$ & 1.82 & $(1.06 ; 3.12)$ & $\mathbf{0 . 0 3}$ & 3.73 & $(1.38 ; 10.08)$ & 0.009 & 2.25 & $(0.90 ; 5.59)$ & 0.08 \\
\hline Body mass index & & & 0.16 & & & 0.32 & & & 0.22 \\
\hline$\leq 18.5 v s .>20.5 \mathrm{~kg} / \mathrm{m}^{2}$ & 1.68 & $(0.91 ; 3.08)$ & 0.09 & 1.74 & $(0.73 ; 4.15)$ & 0.21 & 0.71 & $(0.21 ; 2.35)$ & 0.57 \\
\hline $18.6-20.5 v s .>20.5 \mathrm{~kg} / \mathrm{m}^{2}$ & 1.54 & $(0.87 ; 2.74)$ & 0.14 & 0.80 & $(0.41 ; 5.14)$ & 0.66 & 1.83 & $(0.77 ; 4.37)$ & 0.17 \\
\hline CD4 count & & & 0.67 & & & 0.69 & & & 0.70 \\
\hline$<200 v s .>350 / \mathrm{mm}^{3}$ & 1.36 & $(0.61 ; 3.05)$ & 0.45 & 1.64 & $(0.46 ; 5.89)$ & 0.45 & 0.67 & $(0.19 ; 2.37)$ & 0.54 \\
\hline $200-350 v s .>350 / \mathrm{mm}^{3}$ & 1.12 & $(0.51 ; 2.46)$ & 0.77 & 1.27 & $(0.36 ; 4.49)$ & 0.71 & 0.97 & $(0.31 ; 3.05)$ & 0.96 \\
\hline \multicolumn{10}{|l|}{ Follow-up** } \\
\hline Follow-up CD4 count & & & 0.008 & & & 0.49 & & & 0.01 \\
\hline$<200 v s .>350 / \mathrm{mm}^{3}$ & 2.90 & $(1.44 ; 5.85)$ & 0.003 & 1.57 & $(0.56 ; 4.43)$ & 0.39 & 4.50 & $(1.45 ; 13.97)$ & 0.009 \\
\hline $200-350 v s .>350 / \mathrm{mm}^{3}$ & 1.42 & $(0.76 ; 2.65)$ & 0.27 & 0.90 & $(0.37 ; 2.19)$ & 0.81 & 1.42 & $(0.48 ; 4.17)$ & 0.52 \\
\hline Follow-up viral load. Detect vs. undetect & 2.41 & $(1.26 ; 4.62)$ & 0.008 & 2.45 & $(0.87 ; 6.91)$ & 0.09 & 2.38 & $(0.81 ; 6.97)$ & 0.11 \\
\hline
\end{tabular}

Footnotes for table 2: HR: Hazard Ratio; CI: Confidence interval; TB: tuberculosis

* for baseline variables, results shown are those of the multivariate model including only baseline variables.

** for follow-up variables, results shown are those of the multivariate model including baseline variables and follow-up variables.

Detect: detectable 
Table 3. Factors associated with the risk of mortality after ART initiation: multivariate Cox hazards proportional regression analysis.

\begin{tabular}{lccc}
\hline & \multicolumn{3}{c}{ Mortality } \\
\cline { 2 - 4 } & HR & $(95$ CI $\%)$ & $\mathrm{p}$ \\
\cline { 2 - 4 } & & & \\
Baseline* & & & 0.30 \\
WHO staging and TB history vs. stage lor 2 & & & \\
$\quad$ Stage 3 or 4 without past history of TB & 2.05 & $(0.68 ; 6.13)$ & 0.20 \\
$\quad$ Stage 3 or 4 with past history of TB & 2.67 & $(0.65 ; 11.00)$ & 0.17 \\
Haemoglobin $<90$ vs. $\geq 90$ g/L & 2.66 & $(0.92 ; 7.72)$ & 0.07 \\
Viral load $>5$ vs. $\leq 5$ log 10 copies $/ \mathrm{ml}$ & 1.04 & $(0.38 ; 2.87)$ & 0.94 \\
Body mass index & & & $\mathbf{0 . 0 4}$ \\
$\quad \leq 18.5$ vs. $>20.5 \mathrm{~kg} / \mathrm{m}^{2}$ & & & $\mathbf{0 . 0 2}$ \\
$\quad$ 18.6-20.5 vs. $>20.5 \mathrm{~kg} / \mathrm{m}^{2}$ & $\mathbf{4 . 7 4}$ & $(1.33 ; 16.90)$ & $\mathbf{0}$ \\
CD4 count $<200$ vs. $>200 / \mathrm{mm}^{3 * *}$ & $\mathbf{4 . 1 1}$ & $(1.15 ; 14.68)$ & $\mathbf{0 . 0 3}$ \\
Follow-up*** & $\mathbf{2 . 7 7}$ & $(1.00 ; 7.63)$ & $\mathbf{0 . 0 5}$ \\
Follow-up CD4 count $<200$ vs. $>200 / \mathrm{mm}^{3}$ & & & \\
Follow-up viral load. detect. $v s$. undetect. & $\mathbf{6 . 1 3}$ & $(2.18 ; 17.26)$ & $<\mathbf{0 . 0 0 1}$ \\
Follow-up severe morbidity & $\mathbf{6 . 5 7}$ & $(1.90 ; 22.80)$ & $\mathbf{0 . 0 0 3}$ \\
\hline
\end{tabular}

Footnotes for table 3: HR: Hazard Ratio; CI: Confidence interval; TB: tuberculosis

* for baseline variables, results shown are those of the multivariate model including only baseline variables.

** as there was no death in patients with baseline CD4 count $>350 / \mathrm{mm}^{3}$, baseline CD4 count had to be used in two classes for mortality analyses.

*** for follow-up variables, results shown are those of the multivariate model including baseline variables and follow-up variables.

Detect.: detectable 
Figure 1A. Incidence of severe morbidity on ART according to pre-ART characteristics

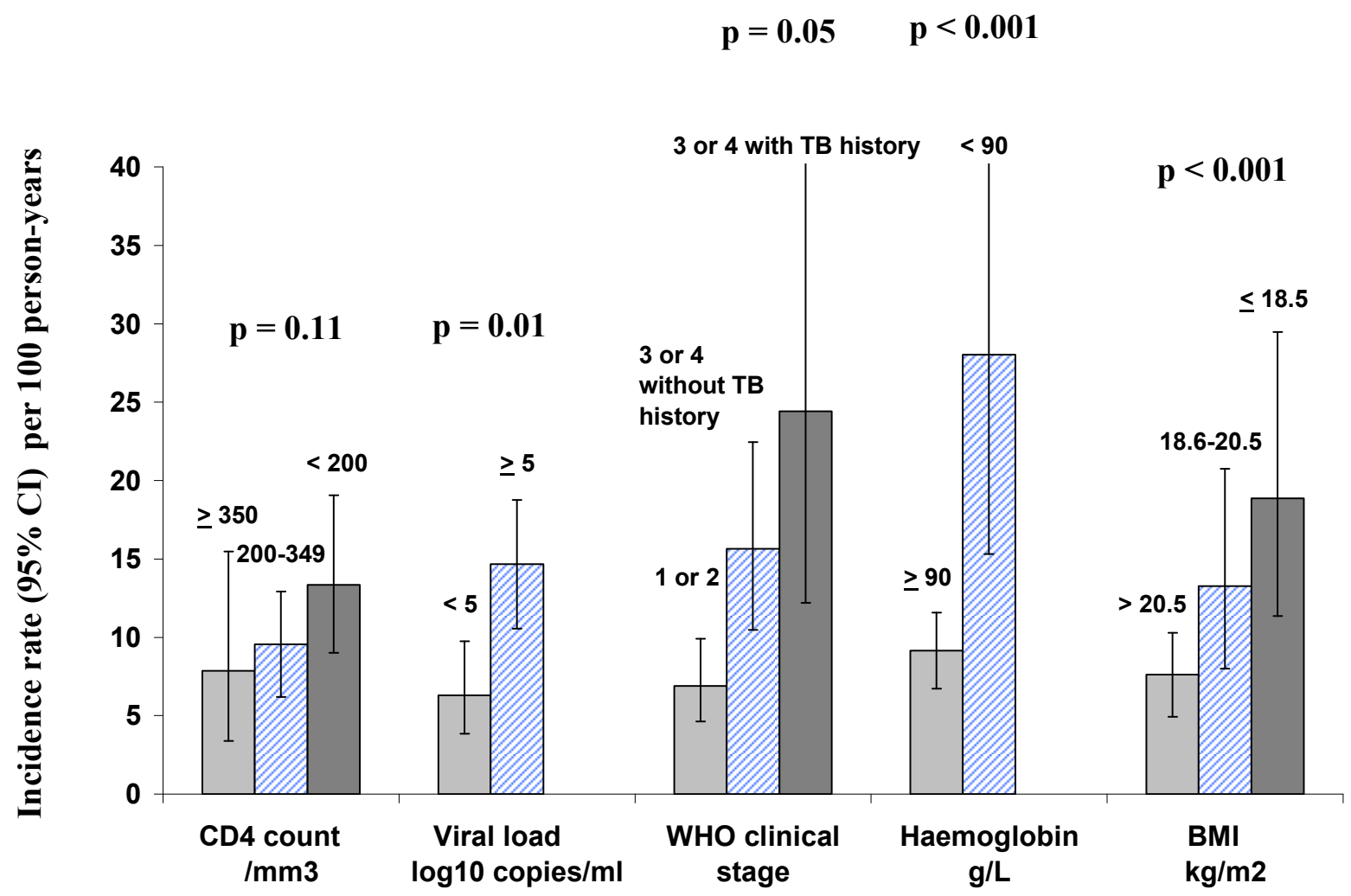

\section{Characteristics on ART initiation}

\section{Footnotes for figure 1A:}

Lines on the bars show the $95 \%$ confidence interval

BMI: body mass index; the $\mathrm{p}$ values shown in the figure are those of the univariate analysis ; results of the multivariate analysis are shown in table 2 
Figure 1B. Incidence of mortality on ART according to pre-ART characteristics

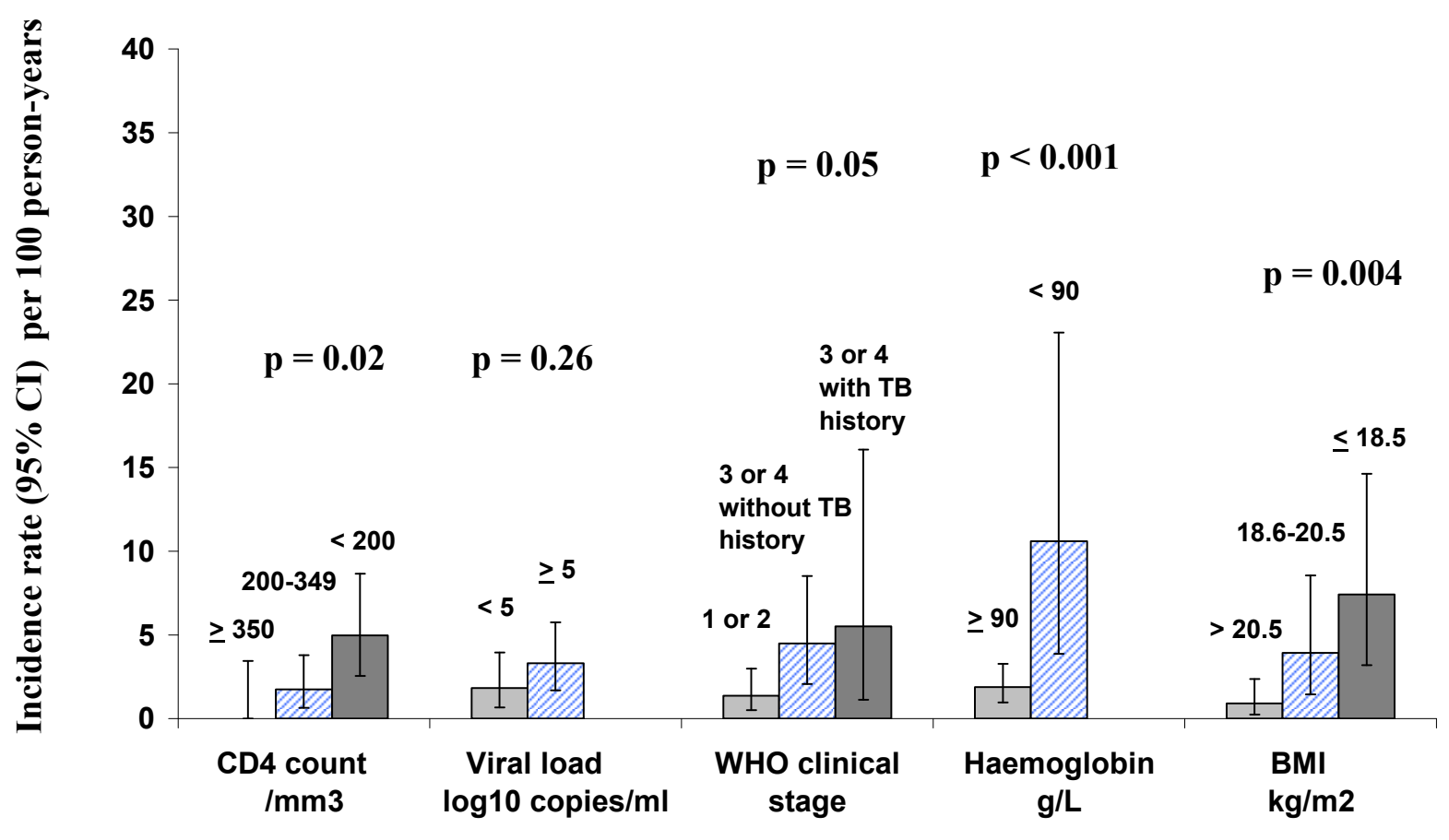

\section{Characteristics on ART initiation}

Footnotes for figure 1B:

Lines on the bars show the $95 \%$ confidence interval

BMI: body mass index; the $p$ values shown in the figure are those of the univariate analysis ; results of the multivariate analysis are shown in table 3 
Figure 2. Incidence of severe morbidity by time since ART initiation

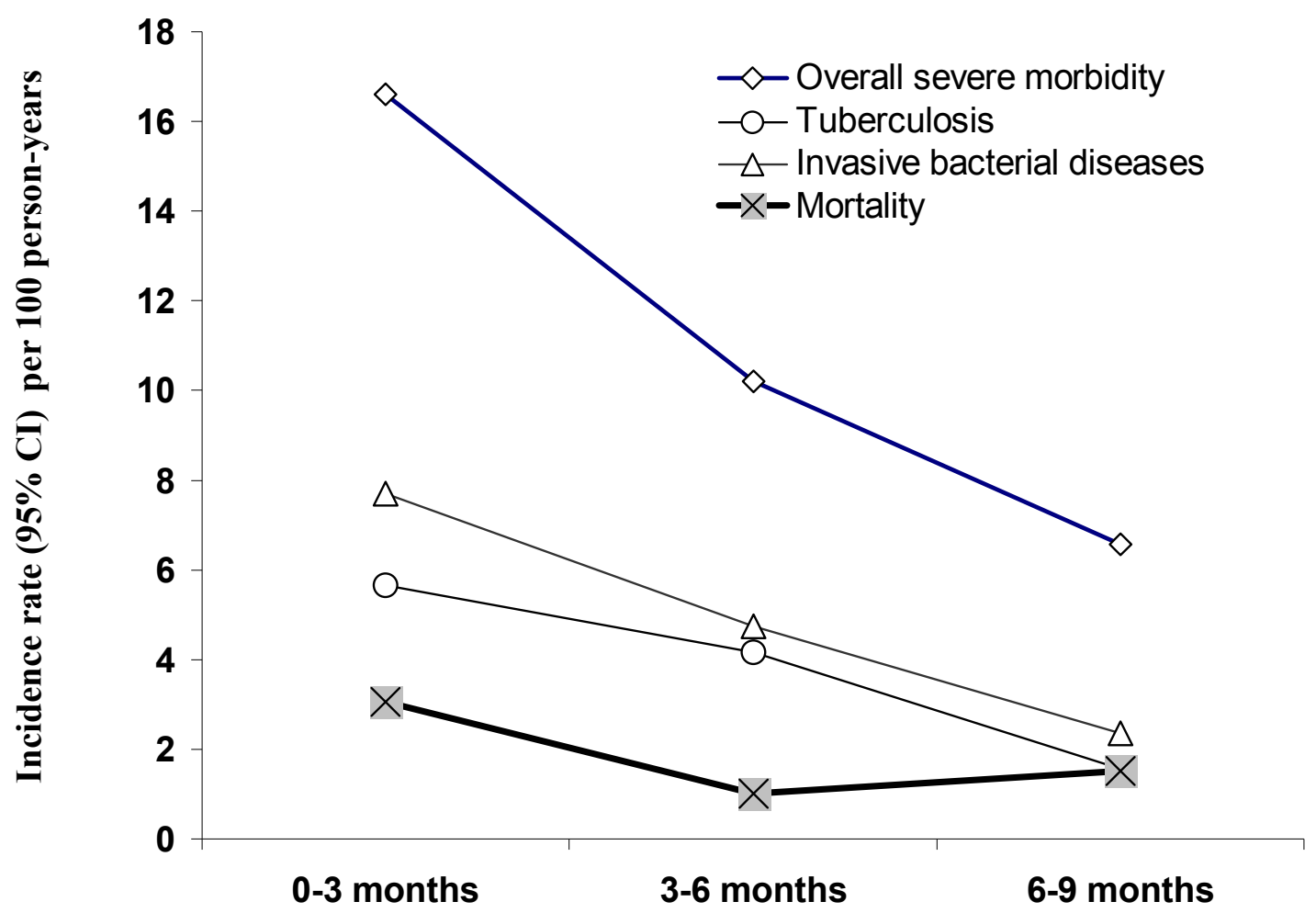

Time since ART initiation 